\title{
Integrated Model of Traceability
}

\author{
Jovana Zoroja \\ Faculty of Economics and Business Zagreb, Croatia \\ Mirjana Pejić Bach \\ Faculty of Economics and Business Zagreb, Croatia \\ Dubravka Omejec \\ O.R.K.A. d.o.o., Osijek, Croatia
}

\begin{abstract}
In last few years, the problem of food safety is becoming bigger while consumers' awareness regarding social responsibility in production, distribution and consumption of food is growing. The main goal for food enterprises is to provide food traceability. This paper focus on traceability systems that can be used to attain the food safety through the systematic monitoring of physical movement of food related raw materials and finished products. In this paper, integrated model of traceability, based on three layers is presented. Our intention is to present concept of traceability which enterprises can use to ensure food safety and food tracking, while traceability concept refers to timely monitoring and accurate recording of product modification process through time and space.
\end{abstract}

Keywords: traceability, legal framework, quality management, supply chain, ICT JEL classification: L67, M11, O 14

\section{Introduction}

Due to the many changes that one has to make before using the natural resources to provide and produce everything that satisfies nutritional needs, food production is not a simple task. According to Sremac (1983) this process involves "a whole range of business operations such as: purchasing and delivery of materials to the manufacturing companies, downloading and storing materials in the warehouse, the flow and processing of materials through each production process faze, finished product storing, packing and distribution to the market according to the demand and requirements of consumers". Therefore, the problem of food safety is becoming bigger than ever (Luning et al., 2015) and it could not be separated from the traceability (Yong et al., 2015). Traceability can be defined as monitoring physical movement of raw materials, intermediate and finished products, accompanied with appropriate data flow about that movement which has to be saved and stored for later use in order to ensure consumers a guarantee of origin or production method (Canavari et. al., 2010; Ringsberg, 2015).

Goal of this paper is to provide an outlook to the food traceability as the process for tracking information. In order to attain this goal, we propose a comprehensive traceability model that consists of three layers: (i) prerequisites of traceability (ii) forms of traceability and (iii) goal of traceability. Food traceability can be fully achieved only when food industry apply standards that provide interoperability. It is important to establish a global, interoperable system for food traceability that will include logistic, safety and quality control (Ringsberg, 2015).

The paper is organized as follows. The first section of the paper is Introduction, where a problem statement related to traceability is presented. In the second section, the elements of integrated model of traceability are presented. In the third 
section, traceability model that consists of three layers is described. The fourth section concludes the paper.

\section{Integrated model of traceability}

There are many definitions of food traceability and according to European Commission (2002) food traceability refers to tracking and following food and ingredients through production, process and distribution. There are several benefits for enterprises when using model of traceability: (i) easily track and locate products, (ii) lower inventory levels, (iii) surveillance of manufacturing processes, (iv) higher efficiency of logistics and distribution processes (Schwagele, 2005).

Systematic monitoring of origin is a generic issue, because its fundamentals are independent of product type, production and control system it serves. Moe (1998) proposed a traceability definition in the food industry as well as introduced the concept of chain and internal monitoring. According to author definition (Moe, 1998), "traceability is the ability to track a product batch and its history through the whole, or part, of a production chain from harvest through transport, storage, processing, distribution and sales (chain traceability) or internally in one of the steps of the chain for example the production step (internal traceability) ".

Traceability is more than transparency of the production or implementation of the quality standards, although both elements are essential for monitoring itself (Opara et al., 2001). The ability to determine each stage on the way to the final product means the strategic management of quality and safety by providing the communications link to identify verify and isolate the cause for products that do not meet the standards and expectations of the customer.

In this paper a comprehensive traceability model that consists of three layers is proposed (Figure 1). A first layer refers to the prerequisites of traceability that consists on legal framework, quality management and ICT infrastructure. A second layer refers to the forms of traceability, which are internal traceability and chain traceability. A third layer refers to the goal of traceability, which is defined as food safety.

Figure 1

Integrated model of traceability

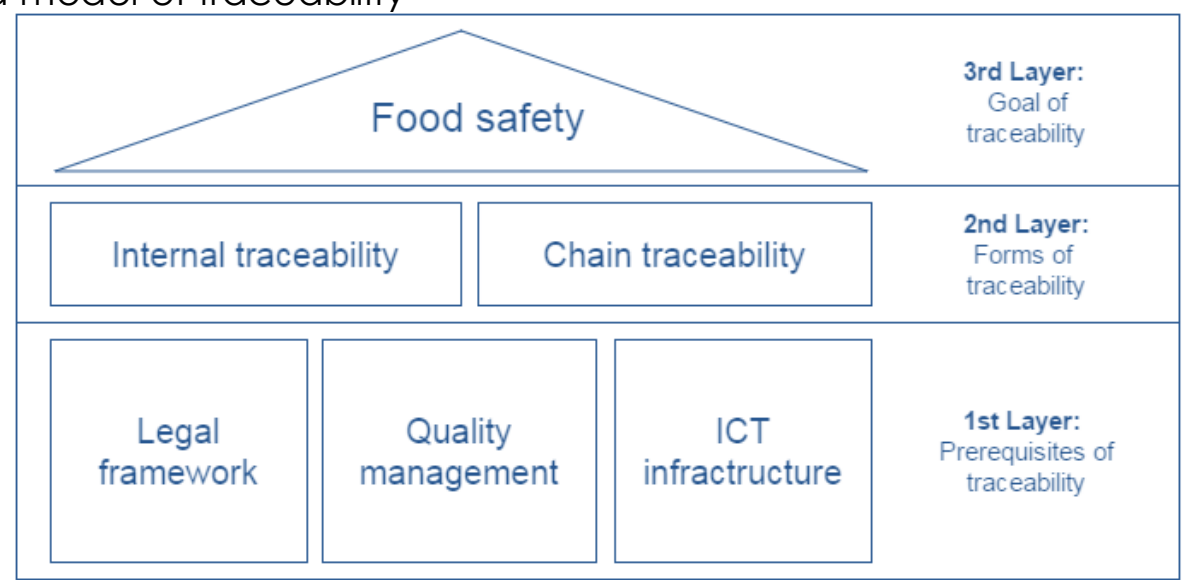

Source: Authors' work

An integrated traceability system presents a valuable tool for enterprises while it lead to higher process control and improvements in operations planning. Therefore, it is crucial to integrate traceability model and supply chain management in order to improve business processes (Wang et al. 2009). 


\section{Prerequisites of traceability}

\section{Legal framework}

European Union members are one of the world's largest food and beverage exporters and importers, which is the reason for setting high safety standards. Traceability is very important while it provides information regarding implicated products and ensures protection of consumers. Therefore, a European Parliament and Council Regulation (EC) 178/2002 in 2005 contain provisions for traceability, with the goal to follow food, feed, and ingredients from production to distribution. In order to have better control under tracking and traceability systems, the newest information technology is used, e. g. radio-frequency identification (RFID) (European Communities, 2004). It also important to mention that in European Union legal framework for food traceability is defined in the European General Food Law (Ringsberg, 2015). In the USA, traceability framework is provided under the Bioterrorism Act and in the Food and Safety Modernization Act (Ringsberg, 2015).According to above facts, it can be concluded that traceability present a significant global economic and legal issue.

\section{Quality management}

Considering that the tracking systems are one of the basic subsystems of quality management systems, one cannot avoid the definition given by the ISO (International Association for Standardization). ISO determines where and to what extent the tracking is particular required as well as establishes and updates the documented procedures for unique identification of individual products and their lots or batches. The ISO 9001 changed the approach to traceability during last 15 years:

- ISO 9001:2000 defined concept as ability to trace the history, application or location of that which is under consideration;

- ISO 9001: 2008 also treats the traceability as "product centered" issues, and it defines it as a monitoring product status throughout product realization;

- ISO 9001:2015 emphasize that maintaining traceability is not a technological issue, and it is considered as a cultural problem and a top management problem.

Traceability is, according to ISO 9001:2015 approaches, closely linked to the identity of the product itself, which is monitored through the stored data, but also to the origin of raw materials from which it was created, the previous processes on products, distribution and location of the product after delivery.

\section{ICT infrastructure}

From the information system perspective, traceability in food manufacturing, transporting and storage is primarily based on the possibility of identifying a single entity (Hu et al., 2013). Entity in traceability contexts refers to the basic concepts that are followed and stored for use in certain situations. Unique identification can be physically marked on the product itself and/or its packaging or the information on the identification can only be stored. Different forms of identification in physical terms are used in practice: e.g. EAN codes or RFID tags (Feng et al., 2013).

Increasing demands for food safety that the market sets before large and dynamic group of participants in food business imply the use of suitable technologies that can ensure traceability within the entire supply chain (Liu et al., 2013). In its complex organization it is characterized with various segments such as e.g.: production, packaging, storage, transport, distribution centers, warehouses, stores. Each 
segment is possibly well covered by IT, but problems arise when they need to bend in a unique system, which should ensure data integrity and accuracy of information. Application solutions for traceability, if any, are based on different technological levels, which depend on financial funds, and that itself is a problem (Mukerjee, 2013).

\section{Forms of traceability}

\section{Internal traceability}

Internal monitoring refers to the specific production process of food companies and movement of products within the scope of the company. Since the finished products are produced or can be produced from raw materials of different quality, it is important, from the standpoint of the traceability concept, to accurately identify the production batch which provides a minimum of traceability information (e.g. production date, production conditions, batch number etc.). It is the basic link between the product and all relevant information on its production and therefore is a key element for concrete, effective and comprehensive concept of traceability (internal or in the entire chain).

It is essential for effective traceability system, that unit codes entering the system (raw materials) unambiguously be associated with those that come out of the system (semi-finished products, finished products) (Kim et al., 1999). It is also important that codes found on finished products, leaving the manufacturing companies, are associated to those used further in logistics and distribution.

\section{Chain traceability}

The application of the traceability concept has no proper impact outside the entire food chain management system (FCM) as it is an integral process. The interruption of collecting information on the characteristics of the process, the location and the product at any time and/or at any place means a reduction or a complete loss of usefulness of such a concept. The structure of the food chain in terms of traceability can be basically defined as a set of points that are connected with events and activities, through which the products and information are moving. Points differ according to transformations or transactions that products are going through (Schwagele, 2005).

It is essential to define the size and content of the entity that is being tracked, identify it appropriately through each location, and keep consistency in its storage. In this way, it is possible in the case of need and on-demand, to reconstruct the events related to the product and retrieves related information from any point in the supply chain and takes appropriate action, which is the main task of the traceability system.

\section{Goal of traceability: Food safety}

Due to the extreme complexity of the flow of materials and goods, it is necessary for it to be constantly controlled and managed (Hu et al., 2013). As the flow of materials through time and space has always been an essential element of every business, the sphere of its follow-up has always been one of the most critical factors for success, especially today when development of the global market erases boundaries which make it increasingly difficult to follow certain activities throughout the so-called supply chain.

Systematic tracking plays a key role in the prevention of new potential damages in the food chain, by identifying and isolating risks and taking corrective action in case that an incident occurs. However, traceability as well as testing or inspection of the product, cannot produce by itself the production safety, and therefore, in case of its 
application in isolation, one can expect inefficiency (Liu et al., 2013). It does not substitute safety management systems or standards for the preservation of quality, but is incorporated in them; successfully complementing them when a problem arises.

\section{Conclusion}

Tracking can be defined as the ability to follow the path of an item as it moves downstream from the production through the supply chain from the beginning to the end. If any problem is suspected, tracking must go as far as the consumer. Traceability as the main prerequisite of the food safety should be treated as an integrated system in order to be efficient. Therefore, we proposed an integrated model of traceability that consists of three levels, incorporating first layer as the prerequisites of traceability (legal framework, quality management and ICT infrastructure), second referring to the forms of traceability (internal traceability and chain traceability), and third layer referring to the food safety as the goal of traceability. Taking into account integrative approach, the traceability systems would provide a more certain path towards the food safety, also enabling management to perceive traceability less as a cost and more as a source of innovation, and opportunity for growth.

\section{References}

1. Canavari, M., Centonze, R., Hingley, M., Spadoni, R. (2010), "Traceability as Part of Competitive Strategy in the Fruit Supply Chain", British Food Journal, 112(2), 171 - 186

2. European Commission (2002), EU Regulation, No. 178/2002 of the European Parliament and the Council of 28 January 2002, Official Journal of the European Communities.

3. European Communities (2004), "Food safety statistics - Inventory of data available in the EU Member States, EFTA and candidate countries", available at: http://edz.bib.uni-mannheim.de/www-edz/pdf/eurostat/04/KS-AZ-04-001-EN-NEN.pdf (03/02/2016)

4. Feng, J., Fu, Z., Wang, Z., XU, M., Zhang, X. (2013), "Development and Evaluation on A RFID-Based Traceability System for Cattle/Beef Quality Safety in China", Food control, 31 (2), 314-325.

5. Hu, J., Zhang, X., Moga, L. M., \& Neculita, M. (2013), "Modeling and implementation of the vegetable supply chain traceability system", Food Control, 30(1), 341-353.

6. Kim, H. M., Fox, M. S., \& Grüninger, M. (1999), "An ontology for quality management-enabling quality problem identification and tracing", BT Technology Journal, 17(4), 131-140.

7. Liu, R., Pieniak, Z., Verbeke, W. (2013), "Consumers' Attitudes and Behavior towards Safe Food in China: A Review", Food Control, 33(1), 93-104.

8. Luning, P. A., Kirezieva, K., Hagelaar, G., Rovira, J., Uyttendaele, M., Jacxsens, L. (2015), "Performance Assessment of Food Safety Management Systems in AnimalBased Food Companies In View Of Their Context Characteristics: A European Study", Food Control, 49, 11-22.

9. Moe, T. (1998), "Perspectives on traceability in food manufacture", Trends in Food Science \& Technology, 9(5), 211-214.

10. Mukerjee, K. (2013), "Customer-Oriented Organizations: A Framework for Innovation", Journal of Business Strategy, 34(3), 49-56.

11. Opara, L. U., Mazaud, F. (2001), "Food Traceability from Field to Plate", Outlook on agriculture, 30(4), 239-247.

12. Ringsberg, H. A. (2015), "Implementation of Global Traceability Standards: Incentives and Opportunities", British Food Journal, $117(7), 1826-1842$. 
13. Schwagele, F. (2005), "Traceability from A European Perspective", Meat Science, $711,164-173$.

14. Sremac, D. (1983), "Općeniti osvrt na poslovnu logistiku" ("A General Overview of the Business Logistics"), Poslovna logistika, Informator, Zagreb.

15. Wang, X., Li, D., O'Brien, C. (2009), "Optimization of Traceability and Operations Planning: An Integrated Model For Perishable Food Production", International Journal of Production Research, 47(1 1), 2865-2886.

16. Yong, L., Xi, Z., Ruo Jun, T., \& Li, A. (2015), "Establishment of Traceability and Supervision System for Import and Export Products and Its Application on Import Food Supervision", Journal of Food Safety and Quality, 6(11), 4312-4317.

\section{About the authors}

Jovana Zoroja, Ph.D. is an Assistant Professor at the Faculty of Economics and Business, University of Zagreb, Department of Informatics. She received PhD in Information Systems at the Faculty of Economics and Business Zagreb with the dissertation thesis "Influence of the Information and Communication Technologies on the Competitiveness of the European Union Countries". She was also educated at the LSE - Summer School in London in the field of Business Development and ICT Innovation. She participated in Erasmus-Preparatory-Visit-Program in Rimini, Italy. Her main research interests are information and communication technology, e-learning, simulation games and simulation modeling. She is actively engaged in number of science projects (FP7-ICT, bilateral cooperation, national projects). Jovana Zoroja published several scientific papers in international and national journals and participated in many scientific international conferences. The author can be contacted at jzoroja@efzg.hr.

Mirjana Pejić Bach, Ph.D. is a Full Professor of system dynamics, managerial simulation games and data mining at the Department of Informatics, Faculty of Economics and Business, University of Zagreb. Her current research areas are simulation modeling, data mining and web content research. She is the (co) author of number of articles in international and national journals. She is actively engaged in number of scientific projects (FP7-ICT, bilateral cooperation, national projects). She is the recipient of the Emerald Literati Network Awards for Excellence 2013 for the paper Influence of strategic approach to BPM on financial and non-financial performance published in Baltic Journal of Management. Mirjana was also educated at MIT Sloan School of Management in the field of System Dynamics Modeling, and at Olivia Group in the field of data mining. The author can be contacted at mpejic@efzg.hr.

Dubravka Omejec, MSc, is a Senior Bussiness Consultant and Financial Manager in ICT company O.R.K.A. d.o.o. in Osijek, specialized for ERP (Enterprise Resource Planning) business solutions. She received MSC in International Economic at the Faculty of Economics and Business Zagreb with the thesis 'Traceability as a condition of entry to the EU market for food producers'. Her main research interests are business process analysis and modeling business integration systems. She participated in business process reengineering for Croatian Pension Insurance Institute and managed number of complex IT project in various businnes areas. She was also educated and received certificate in financial and management accounting and is engaged as consultant in finances, planning and budgeting project implementation. Author can be contacted at domejec@orka.hr. 